"Using the Branch and Section

structure has a very real relevance

to controlling our future."

\title{
The membership is the real strength of the BDA
}

I expect, like me, you have heard the words in the title above said a number of times. But it wasn't until I became editor of the $B D J$ that I really understood what they meant. Before then I, like many others I suspect, always thought of the BDA as Wimpole Street (or one of the offices in Scotland, Wales and Northern Ireland). Hence the oft-repeated question 'When are the BDA going to do something about..?'

Of course the demand should have been 'When are we going to do something about..?' because we the members are the BDA. Unlike the popular view of national politics (where we seem so helpless in the face of what appears to be a predetermined pathway decided by those at the top) we do have influence through the Branch and Section structure. Or so we are led to believe - but in the real world is that true? Is there any point in belonging to a BDA Section and does it really make any difference to what happens in dentistry?

I suppose the answer to the question depends on your definition of how dentistry grows, changes and develops. If you believe that what happens is mainly controlled by a few people in BDA offices in Wimpole Street and around the UK, then supporting your Section seems to be simply a social opportunity with the chance of a meal and a couple of CPD hours. Nothing wrong with that, but it is not very satisfying, is it? If, on the other hand, you believe that the grass roots ultimately direct the course of dentistry by how we think and what we do, then supporting some kind of organisation is essential if we are going to make a difference. Perhaps using the Branch and Section structure has a very real relevance to controlling our future.

I have visited many BDA Sections over the years, and I can confirm that they are, indeed, very different from each other. Yet I am also convinced that despite these differences there is something very special about a BDA Section that you won't experience anywhere else. A postgraduate course is definitely not the same, nor is a study club. I do not believe those who claim there is no longer a need for BDA Sections because of the increase in postgraduate courses and meetings. I know from my own experiences that the essence of a BDA Section contains more than simply CPD points, even the less active Sections.

So what is this 'magic' difference? It is hard to define, to capture, to put into words. It seems to be a blend of fellowship, a strength of purpose and (surprisingly) a unity sprinkled with professionalism. Sometimes it is pretty well hidden by a lacklustre approach, sometimes it shines through a well-run and enthusiastic Section. And sadly (in my view) it seems unaware of its own power. But I am convinced it is there.

Yet I have never heard anyone speak of this 'hidden' strength. I was not really aware of it myself until I attended a BDA Section meeting a few years ago, and even then I have done nothing about my realisation until now. I suspect that I, like most of us, was letting my perception of the past affect me. Surely now, at this time of change that is possibly the greatest since 1948 , it is the moment for us as a profession to decide to do something about it - and the BDA is the most obvious route for us to use.

If, as I stated at the outset of this leader, the strength of the BDA is its membership then Sections are where we, the membership, can really make the difference. Support from the staff at HQ can help Sections become more attractive. BDA members can choose a Section that is more convenient to them if their appointed Section does not suit (contact Sue Jones (s.jones@ bda.org) if you wish to change). Most importantly of all, if your Section is not doing what you feel it should then don't just ignore it, make your views known. If we don't at least support our profession we can hardly complain about what happens to us in the future.

After all, we are the BDA.

Mike Grace Immediate Past Editor, BDJ

DOI: $10.1038 /$ bdj.2007.530 